\title{
Aromatic characterization of brazilian sparkling wines using olfactometry and a sensory panel
}

\author{
Marcos Gabbardo ${ }^{1}$, Franco Battistutta ${ }^{2}$, Esther Theisen Gabbardo ${ }^{3}$, Lara Tat $^{2}$, e Emilio Celotti ${ }^{2}$ \\ ${ }^{1}$ UNIPAMPA Campus Dom Pedrito, 96450-00 Rua 21 de abril, 80 Dom Pedrito-RS, Brazil \\ ${ }^{2}$ UNIUD Departimento di Scienza degli Almineti, 33100 via Sondrio 8, Udine-FVG, Italy \\ ${ }^{3}$ Guatambu, Estância do Vinho, 96450-000, Km 265 BR-392, Dom Pedrito-RS, Brazil
}

\begin{abstract}
Brazilian sparkling wines, which currently account for $30 \%$ of the national production of fine wines, have been traditionally produced in the southern region since the 1910s. The objective of the present study was to establish sparkling wine typicality via aroma characterization by comparing quantitative and descriptive techniques for the main aromatic compounds. Sparkling wines from the major producing regions of Brazil were tested by two sensory panels, followed by gas chromatography analysis that allowed elucidation of their aromatic basis. Solid-phase microextraction was used for the extraction of the compounds, followed by detection using gas chromatography (GC), olfactometry and mass spectrometry (MS). Olfactometry and gas chromatography-mass spectrometry (GC-MS) identified 25 aromatic areas and 26 aromatic compounds, respectively. Fruity and floral aromas were highlighted by olfactometry. Most often, Brazilian and Italian sensory analysis panels cited pineapple and roasted or apple and fruit individual descriptors, respectively.
\end{abstract}

\section{Introduction}

Brazilian sparkling wines are the product of excellence for Brazilian winemaking, as recognized by awards in international enological contests and an increase in production and sales; currently, sparkling wines account for $30 \%$ of the fine wine production in Brazil.

Over the past 10 years, worldwide production and consumption of sparkling wines has increased by $40 \%$ and $30 \%$, respectively. In 2013, 17.6 million hectoliters of sparkling wine (7\% of the total wine production) were produced worldwide. In Brazil, sparkling wine production increased $248 \%$ over the past 10 years, holding an $80 \%$ share of the domestic market wine [1].

Brazilian sparkling wines are traditionally produced in the Serra Gaúcha region using traditional methods and the Charmat method. Products with the characteristics of young wines up to the extended maturation of the lees are sought. The most commonly used varieties are Chardonnay, Pinot Noir and Riesling Italico. The resulting wines primarily fall under the Brut classification, with mean sugar contents of $8 \mathrm{~g} . \mathrm{L}^{-1}$ [2]. The Campanha Gaúcha region, which is located next to Uruguay, has gained prominence in recent years for the production of sparkling wines, and it primarily uses the traditional method. Aromatic chemical compounds contribute to the typicality of Brazilian sparkling wines. Because of its complexity and significance at the time of consumption, it is necessary to understand the aromatic composition of these wines and what compounds actually contribute to product quality. For compounds to be perceived by the olfactory organ, they must be volatile, soluble, aromatic, and present in perceivable concentrations. The aroma is evaluated in terms of intensity, fineness and persistence.
Gas chromatography combined with olfactometry (GC-O), also known as "sniffing", is a major breakthrough that allows the identification and quantification of the main compounds that have an olfactory impact in wines. GC$\mathrm{O}$ quantifies the impact of odorous compounds in foods using the human nose as a detector $[3,4]$. It provides an understanding of the chemical basis of the aroma; however, not all of the wines produced worldwide have been evaluated using this technique.

The human nose is typically more sensitive than any instrument detector, and olfactometry is considered a powerful tool for measuring any odoriferous compound [3]. Traditional sensory analysis is performed using consolidated international evaluation criteria.

Furthermore, the characterization of the volatile fractions from wines has significantly evolved with the use of gas chromatography coupled to mass spectrometry (GC-MS). This technique allows the exact determination of compound profiles and quantities of the wine volatile fractions [5] but not their impact. Hence, the importance of GC-O associated with descriptive sensory analysis [6] serves as a comparison between classical sensory analysis and the individual quantification performed by GC-MS.

The objective of the present study was to determine the main active aromatic compounds in Brazilian quality sparkling wines and the profile of volatile compounds that have a sensory impact in the wines. We used sensory panels of trained evaluators in Brazil and Italy, GC-MS and GC-O to identify the volatile compounds that have an impact on human senses.

\section{Materials and methods}

Six Brazilian sparkling wines from the Campanha Gaúcha (2 samples) and Serra Gaúcha (4 samples) regions were 
analyzed. Three samples were produced using traditional methods, and three were produced using the Charmat method. They were elaborated from different cultivars, including Chardonnay, Pinot Noir and Riesling Italico. All of the wines were classified as Brut.

Sparkling wines were kept at $4{ }^{\circ} \mathrm{C}$ for analysis. After the bottles were opened, $10 \mathrm{~mL}$ of each sparkling wine was used for aroma extraction using solid-phase microextraction (SPME). The sparkling wines were placed in a $50 \mathrm{~mL}$ glass vial with septum screwcaps; $2.5 \mathrm{~g}$ of sodium chloride and a magnetic stirrer were added to the vial to facilitate aroma release. After capping, the vial was placed in a glass beaker that contained water at $40^{\circ} \mathrm{C}$, which was maintained using a heating plate, and magnetic stirring was performed for 15 minutes. A divinylbenzene/carboxen/polydimethylsiloxane three-phase fiber, which is ideal for identifying aromas in wine [7], was exposed to the head space for 15 minutes. Then, the fiber was placed in the chromatograph injector for 2 minutes at $250{ }^{\circ} \mathrm{C}$ for desorption of volatile compounds for GC-O.

GC-O was used to identify the significant olfactory areas. The effluent at the end of the chromatographic column was split in two using a Y-connector, which directed part of the flow towards either the flame ionization detector (FID) or the olfactometric detector. For the latter, in addition to the GC effluent, a stream of humidified air and nitrogen was placed at the column outlet to move the analytes to the top towards the "nose". The GC effluent was continuously inhaled by three evaluators (two women and one man) over 10 minute cycles in duplicate to avoid fatigue. When an aroma was detected, the operator pressed a button that generated an electrical pulse, and the operator attempted to recognize the aroma (e.g., fungal aroma, vanilla aroma, etc.) and classify the intensity of the perceived sensation (weak, mild and intense).

For the GC-O analysis, a Carlo Erba HRGC 8560 Mega Series 2 gas chromatograph was used. The instrument was equipped with an Econo-PAC column (CE-wax) from Alltech (30 $\mathrm{m} \times 0.25 \mathrm{~mm}$ i.d., 12:25 film thickness). The operating conditions were as follows: a $250{ }^{\circ} \mathrm{C}$ injector temperature, a $240{ }^{\circ} \mathrm{C}$ detector temperature, splitless injection mode for $70 \mathrm{sec}$, helium carrier gas, and a $35 \mathrm{~cm} / \mathrm{sec}$ linear velocity. The oven temperature conditions included $40^{\circ} \mathrm{C}$ for $5 \mathrm{~min}$, a temperature ramp from $40^{\circ} \mathrm{C}$ to $240^{\circ} \mathrm{C}$ at $4{ }^{\circ} \mathrm{C} / \mathrm{min}$, and a final isothermal holding time of $7 \mathrm{~min}$ at $240^{\circ} \mathrm{C}$.

The volatile aromatic fraction was determined via SPME-GC-MS using a three-phase $2 \mathrm{~cm}$ fiber (Supelco) at a sampling temperature of $40^{\circ} \mathrm{C}$ for 15 minutes. Samples were analyzed in duplicate using a GC system (Agilent Technologies Italia S.p.A., Cernusco sul Naviglio, MI, Italy) that comprised an auto sampler (Agilent PAL RSI 85) with 45 slots, a gas chromatograph (GC Agilent 7890B) equipped with two columns (DB-5MS and VFWAX, both $30 \mathrm{~m} \times 0.25 \mathrm{~mm}$ i.d., film thickness $0.5 \mu \mathrm{m}$ ), and a mass spectrometer (Agilent 5977A) that included an electron impact source and a quadrupole analyzer.

The conditions for GC included an isothermal start at $40^{\circ} \mathrm{C}$ for 5 minutes, followed by a temperature ramp from $40^{\circ} \mathrm{C}$ to $240{ }^{\circ} \mathrm{C}$ at $4{ }^{\circ} \mathrm{C} / \mathrm{min}$ and a final isothermal holding time of 10 minutes at $240^{\circ} \mathrm{C}$. The conditions also included a $250{ }^{\circ} \mathrm{C}$ injector temperature, helium carrier gas at a flow rate of $1 \mathrm{~mL} / \mathrm{min}$, purge-less, splitless injection mode, injection in a VF-WAX column, $175^{\circ} \mathrm{C}$ and $150^{\circ} \mathrm{C}$ source and quadrupole temperatures, respectively, and a $280^{\circ} \mathrm{C}$ transfer line temperature.

The mass spectrometer operated in SCAN mode (with a scan range of $\mathrm{m} / \mathrm{z}$ 30-350). The volatile compounds were identified using the NIST 08 Mass Spectral Library and via comparison with the literature. Agilent MassHunter Qualitative Analysis B.06.00 was used for data acquisition and processing, and mean values were calculated using Excel $^{\circledR} 2013$.

An open form was used for the sensory evaluation to describe the olfactory portion using the main aromatic descriptors. The Brazilian evaluation panel consisted of 12 evaluators ( 5 men and 7 women) with a background in Enology and at least 3 years of experience in wine evaluation. The Italian panel also comprised 12 trained evaluators (6 men and 6 women) who were participants in a wine tasting group. The evaluators were asked to assign up to 4 aromatic descriptors to describe the perceived aroma of each sample.

The descriptors obtained were classified into 10 categories: fruity, roasted, sweet, nutty, milk/yeast, flour, defective, floral, herbaceous/plant and others. The top five categories were ranked by the number of sample descriptors and their overall percentage. The most representative specific descriptor of the most representative categories of a given sample was highlighted (particularly the number of times it was described) to characterize the typicality of each sparkling wine. Each evaluator panel (Brazil and Italy) performed the classification separately.

\section{Results and discussion}

The association between the olfactometric ratings and GC enabled the identification of 25 different areas (Table 1), which were each characterized by the evaluation panels in different intensities and with various aromatic descriptors. Thirteen areas were classified as "intense" by some evaluators, which highlighted their importance in the aromatic profile.

The majority of aromatic areas were associated with fruit descriptors, but floral aromas were also emphasized; these aromas often contribute to the elegance of sparkling wine and are highly valued by both consumers and experts [8]. Vegetative aromas were also described, especially for the retention times of 14.7 and $22.7 \mathrm{~min}$, and are likely related to hexanol and pyrazines, which have a low perception threshold that enables their individualization in wine sensory analysis.

Some unpleasant aroma descriptors were ascribed to the products, including unpleasant, chicken stock, and sulfury aromas. These descriptors often mask qualitative aromas in sparkling wines [9] and are not described by panels of evaluators; thus, an olfactometry study can help producers enhance the product's qualitative aromas by limiting the amount of these compounds during processing.

Table 2 summarizes the GC-MS results. The ester found in the highest concentrations was ethyl acetate, with a similar value to that found by [10] in aged Cavas. Sparkling wine 5 exhibited the highest mean value, which was almost double that of the lowest value in sparkling wine 6 . Ethyl octanoate concentrations varied significantly, with sparkling wine 2 containing three times the amount 
Table 1. Gas chromatography-olfactometry identification of aroma descriptors and their intensities in Brazilian sparkling wines.

\begin{tabular}{|c|c|c|c|c|c|c|c|}
\hline \multirow[t]{2}{*}{$\mathbf{R T} \dagger$} & \multirow[t]{2}{*}{ Aromatic descriptors used by the evaluators } & \multicolumn{6}{|c|}{$\begin{array}{l}\text { Maximum descriptor aromatic level for each sparkling wine } \\
\text { (Intense, Medium and Wispy) }\end{array}$} \\
\hline & & SW1 & SW2 & SW3 & SW4 & SW5 & SW6 \\
\hline 5.8 & Strawberry, creamy, sweet & I & I & I & I & $\mathrm{W}$ & I \\
\hline 6.3 & Sweet, floral & M & M & I & I & M & I \\
\hline 7.8 & Dry leaf & & & & M & & \\
\hline 11.6 & Unpleasant, sulfury & I & M & I & M & M & I \\
\hline 12.5 & Floral, sweet, strawberry & M & M & I & M & $\mathrm{I}$ & I \\
\hline 14.7 & Vegetative, Fungus, tea & $\mathrm{W}$ & I & M & $\mathrm{W}$ & & W \\
\hline 16.7 & Lemongrass, sweet & & & & & W & M \\
\hline 18.8 & Fruity, mushroom, vegetative & M & W & W & W & M & \\
\hline 19.8 & Earthy, vegetative & W & $\mathrm{M}$ & & I & M & I \\
\hline 20.8 & Bread, unknown, dairy, fungus & $\mathrm{W}$ & & M & M & $\mathrm{W}$ & W \\
\hline 21.7 & Mint, floral, violet, herbaceous & & M & M & M & M & W \\
\hline 22.7 & Green bell pepper, herbaceous, roses & I & M & I & M & M & I \\
\hline 23.9 & Orange, plum, apple, floral & M & & M & $\mathrm{W}$ & $\mathrm{W}$ & \\
\hline 26.4 & Sweet, syrupy & & I & & & & \\
\hline 27.7 & Chicken stock, dairy, marjoram & I & & & M & I & I \\
\hline 28.2 & Roses, walnuts, herbaceous, cardboard & $\mathrm{W}$ & W & W & $\mathrm{W}$ & M & $\mathrm{W}$ \\
\hline 29.1 & Dry leaf, green tea, herbaceous & M & M & M & & W & W \\
\hline $\begin{array}{l}31.7 \\
31.8\end{array}$ & Fig jam, fruit jelly, peach tea & M & I & I & I & M & I \\
\hline 33.6 & Candy, sweet, floral, roses, fruity & M & W & M & I & I & W \\
\hline 34.4 & Roses, violet, geranium, poached orange & I & I & $\mathrm{I}$ & M & I & I \\
\hline 38.5 & Hay, almonds, sweet & & M & I & $\mathrm{W}$ & & \\
\hline 40.8 & Dry leaf, floral & M & & & & W & W \\
\hline 43.5 & Toasted bread, coffee, citrusy & & W & W & & M & W \\
\hline 46.3 & Orange, floral, undefined & M & & & & W & M \\
\hline 52.8 & Sweet, eucalyptus, unpleasant & & & W & & $\mathrm{W}$ & \\
\hline
\end{tabular}

$\dagger$ RT Retention time.

Table 2. Aromatic compounds and mean values that were quantified using SPME-GC-MS for each evaluated Brazilian sparkling wine.

\begin{tabular}{|c|c|c|c|c|c|c|c|c|}
\hline \multirow[t]{2}{*}{ Chemical compounds } & \multirow[t]{2}{*}{$\mathbf{R T} \dagger$} & \multirow[t]{2}{*}{ Wine aromatic descriptor $\ddagger$} & \multicolumn{6}{|c|}{ Mean concentration of aromatic compounds $\left(\mathrm{mg.} \mathrm{L}^{-1}\right)$} \\
\hline & & & SW1 & SW2 & SW3 & SW4 & SW5 & SW6 \\
\hline Ethyl acetate & 4.083 & $\begin{array}{l}\text { Fruity (apple, raspberry } \\
\text { and strawberry) }\end{array}$ & 23.88 & 21.79 & 28.72 & 22.42 & 34.71 & 19.32 \\
\hline Ethyl butanoate & 8.688 & Pineapple, apple and cheese & 1.26 & 1.03 & 1.06 & 0.93 & 0.68 & 0.86 \\
\hline 1-Propanol & 8.79 & Alcoholic & & 0.76 & 1.23 & 0.72 & 1.53 & 1.33 \\
\hline Isobutanol & 10.885 & Alcoholic & 2.07 & 2.96 & 2.52 & 4.19 & 1.87 & 4.01 \\
\hline Isoamyl acetate & 11.93 & Banana or pear & & & & 1.12 & 0.97 & \\
\hline Isoamyl alcohol & 15.276 & Malty, enamel, pungent & 50.32 & 58.68 & 48.05 & 52.20 & 39.07 & 67.48 \\
\hline Ethyl hexanoate & 16.219 & $\begin{array}{l}\text { Floral/fruity (pineapple, blackberry, } \\
\text { apple and strawberry) }\end{array}$ & 6.11 & 6.87 & 6.68 & 4.75 & 3.16 & 5.93 \\
\hline Ethyl lactate & 20.253 & Butter & 4.06 & 3.43 & 10.67 & 8.45 & 2.06 & 11.7 \\
\hline 1-Hexanol & 20.493 & Freshly cut grass & 2.72 & 3.94 & 2.16 & 4.59 & 4.28 & 4.83 \\
\hline Ethyl octanoate & 23.318 & Sweet aromas & 18.23 & 25.05 & 22.64 & 13.37 & 7.01 & 15.22 \\
\hline Furfural & 24.45 & Yeast & 0.95 & 1.12 & 1.07 & 1.26 & 1.00 & 1.12 \\
\hline 2-ethyl-hexanol & 25.059 & Earthy, lightly floral & 0.68 & 0.85 & 0.92 & 0.93 & 0.73 & 0.83 \\
\hline 2, 3-butanediol & 26.682 & Sweet & & & & & & 0.68 \\
\hline Isoamyl lactate & 27.637 & Fruity & & & 0.78 & & & 0.85 \\
\hline 2-ethyl-furanoate & 29.34 & Aged & 0.76 & & & & & \\
\hline Ethyl decanoate & 29.663 & Floral & 5.20 & 5.71 & 6.99 & 2.70 & 1.56 & 2.53 \\
\hline Diethyl succinate & 30.842 & Aged & 22.76 & 35.10 & 20.86 & 16.95 & 11.90 & 38.23 \\
\hline 4-ethyldecanoate & 31.207 & Pear and vegetative & & & 1.32 & & & \\
\hline Phenylethyl acetate & 34.827 & Apple and honey & & & & 0.81 & & \\
\hline Hexanoic acid & 35.663 & Animal, waxy, unpleasant & 8.74 & 9.83 & 8.80 & 7.38 & 6.42 & 5.20 \\
\hline Phenylethanol & 37.366 & Roses and honey & 11.57 & 18.25 & 11.13 & 0.00 & 8.26 & 17.32 \\
\hline Diethyl malate & 40.59 & Toffee & 1.16 & 0.88 & & & 0.64 & 0.73 \\
\hline Octanoic acid & 41.085 & Waxy and coconut & 35.30 & 38.08 & 41.99 & 28.24 & 21.49 & 20.74 \\
\hline Decanoic acid & 45.998 & Animal, waxy and palm oil & 8.96 & 7.85 & 13.33 & 3.95 & 2.91 & 3.34 \\
\hline Caproleic acid & 47.361 & Waxy or unripe fruit & & & 0.76 & & & \\
\hline Phthalic acid & 54.695 & & & & 0.78 & & & \\
\hline
\end{tabular}

$\dagger$ Retention time. $\ddagger[14]$. 
Table 3. Main aromatic categories and most described aromatic descriptors by the Brazilian panel.

\begin{tabular}{cccccc}
\hline Sample & \multicolumn{5}{c}{$\begin{array}{c}\text { Aromatic categories and their percentage in decreasing order. } \\
\text { Most described individual descriptor and number of times cited }\end{array}$} \\
\hline SW 1 & FRUITY 27\% & ROASTED 14\% & SWEET14\% & FLORAL 11\% & DAIRY 8\% \\
& Pineapple 3x & Roasted 5x & Sweet 2x & White flowers 2x & Yeast 2x \\
SW 2 & FRUITY 29\% & SWEET 17\% & FLOUR 12\% & FLORAL12\% & ROASTED 9\% \\
& Pear 4x & Honey 2x & Bread 3x & Floral 3x & Roasted 2x \\
SW 3 & SWEET26\% & DEFECTS 14\% & FRUITY 12\% & NUTTY 12\% & ROASTED 12\% \\
& Honey 3x & Chemical 2x & Fruity 3x & Almond 2x & Roasted 3x \\
SW 4 & ROASTED 17\% & FRUITY 15\% & NUTS 12\% & FLOUR 12\% & DAIRY 12\% \\
& Roasted 6x & Pineapple 3x & Almond 2x & Bread 5x & Yeast 3x \\
SW 5 & FRUITY42\% & SWEET 17\% & FLORAL7\% & FLOUR 7\% & ROASTED 7\% \\
& Peach 3x & Fruit in syrup 4x & Floral 2x & Toasted bread 2x & Roasted coffee 2x \\
SW 6 & FRUITY 27\% & ROASTED 18\% & FLOUR 11\% & NUTS 9\% & SWEET 9\% \\
& Pineapple 3x & Roasted 5x & Bread 4x & Walnuts 3x & Syrup 2x \\
\hline
\end{tabular}

Table 4. Main aromatic categories and most described aromatic descriptors by the Italian panel.

\begin{tabular}{|c|c|c|c|c|c|}
\hline \multirow{3}{*}{$\begin{array}{l}\text { Sample } \\
\text { Sample } 1\end{array}$} & \multicolumn{5}{|c|}{$\begin{array}{l}\text { Aromatic categories and their percentage in decreasing order. } \\
\text { Most described individual descriptor and number of references. }\end{array}$} \\
\hline & FRUITY 30\% & SWEET $20 \%$ & FLORAL $11 \%$ & DAIRY 9\% & NUTS 9\% \\
\hline & Citrusy 3x & Vanilla 3x & Floral 3x & Yeast 4x & Hazelnut $2 \mathrm{x}$ \\
\hline \multirow[t]{2}{*}{ Sample 2} & FRUITY $21 \%$ & FLORAL $19 \%$ & VEGETATIVE $12 \%$ & SWEET $12 \%$ & NUTS 9\% \\
\hline & Apple 2x & Floral $3 \mathrm{x}$ & Vegetative $2 \mathrm{x}$ & Honey 3x & Hazelnut 2x \\
\hline \multirow[t]{2}{*}{ Sample 3} & FRUITY $29 \%$ & VEGETATIVE $17 \%$ & DAIRY $12 \%$ & FLORAL $12 \%$ & ROASTED 9\% \\
\hline & Apple $3 \mathrm{x}$ & Olive $2 \mathrm{X}$ & Yeast $4 \mathrm{x}$ & Flower 2x & Roasted 2x \\
\hline \multirow[t]{2}{*}{ Sample 4} & FRUITY $31 \%$ & FLOUR 20\% & SWEET13\% & VEGETATIVE $11 \%$ & NUTTY 6\% \\
\hline & Apple 5x & Bread crust $6 x$ & Vanilla $3 \mathrm{x}$ & Dry leaf $3 x$ & Nutty 2x \\
\hline \multirow[t]{2}{*}{ Sample 5} & FRUITY $26 \%$ & SWEET 15\% & VEGETATIVE $12 \%$ & FLORAL $12 \%$ & FLOUR $10 \%$ \\
\hline & Ripe fruit 3x & Poached apple $2 x$ & Herbs $3 \mathrm{x}$ & FDry flower $2 \mathrm{x}$ & Bread crust $2 x$ \\
\hline \multirow[t]{2}{*}{ Sample 6} & ROASTED $23 \%$ & FRUITY 17\% & VEGETATIVE $12 \%$ & SWEET $12 \%$ & FLOUR $10 \%$ \\
\hline & Roasted 3x & Fruit $2 \mathrm{x}$ & Vegetative $3 \mathrm{x}$ & Poached fruit $2 \mathrm{x}$ & Bread 2x \\
\hline
\end{tabular}

found in sparkling wine 5. Ethyl butanoate values were similar for all sparkling wines. Isoamyl acetate was only found in sparkling wines 4 and 5 in concentrations similar to those described in [10].

The mean concentration values of isoamyl, 1-propanol and isobutanol alcohols were lower than those [11], who studied sparkling wines from non-traditional cultivars. The mean values for hexanol were higher than those described by Torrens [10] and Perez-Magariño [11], which can be explained by the climatic conditions in southern Brazil. However, the values are similar to those described in Ganss [12].

Compounds with dairy and yeast aromas, such as ethyl lactate and furfural, respectively, serve as markers of the sparkling wine production process, particularly the maturation stage. Torrens [10] also observed similar furfural contents in 18 month-aged Cavas.

Floral aromas that originate from esters, such as ethyl decanoate and ethyl hexanoate, showed higher values than those described in other studies [10,11]. This unique characteristic of Brazilian sparkling wines may be due to the precursors found in grapes, which are emphasized after yeast action. Another interesting compound is 2phenylethanol, which is associated with the aroma of roses and honey. It reached the highest value in sparkling wine 2 and was not identified in sparkling wine 4; the maximum value is similar to that found by others authors $[10,13]$.

Finally, SPME-GC-MS analysis allowed the identification and quantification of the acids, the mean value of which was well above those described in other studies $[10,11]$. For certain concentrations, the aroma of these compounds decreases the quality of the aromatic profile of sparkling wines.

The aromatic description of sparkling wines, as established by the different evaluator groups, is shown in Tables 3 and 4. Fruity descriptors were predominant. Interestingly, there was a significant presence of roasted aroma descriptors, which are usually due to aging on lees and on oak, demonstrating that certain products develop for a long time [8]. Furthermore, several evaluators described sweet aromas, which suggests good grape maturation and a quality winemaking process. Product complexity was also demonstrated by the description of floral and vegetative aromas. Defective aromas were described in only two samples, and when taken in conjunction with the results of the other evaluation panel, this category was not ranked among the top 5 .

Regarding individual descriptors, the Brazilian evaluators highlighted the pineapple and roasted aromas (Table 3), and the Italian group cited apple and fruit descriptors most often (Table 4). Additionally, the Italian group described more vegetative aromas, and the Brazilian group described a hint of bread.

\section{Conclusions}

1. GC-O enabled the evaluators to identify 25 aromatic stimuli, which were described and characterized in terms of their intensity. The majority of the stimuli were characterized as fruity and floral aromas.

2. SPME-GC-MS identified 26 different aromatic compounds, particularly aromatic esters. 
3. Regarding the individual descriptors, the Brazilian evaluation panel described mostly pineapple and roasted aromas, whereas the Italian panel described apple and fruit aromas.

\section{References}

[1] IBRAVIN. (2015) Informativo Sacarolha. Year 6, Number 15. http://www.ibravin.org.br/ admin/arquivos/sacarolhas/1456835080.pdf

[2] M. Gabbardo, E. Celotti, Ciên. e Téc. Vitiv. 30, 94-101 (2015)

[3] 1.D. Falcão, G. Revel, J.P. Rosier, M.T. BordignonLuiz, Fd Ch. 107, 497-505 (2008)

[4] V. Ferreira, F. San Juan, A. Escudero, L. Cullere, P. Fernandez-Zurbano, M. P. Saenz-Navajas, J. Cacho, Journal of Agricultural and Food Chemistry 57, 7490-7498 (2009)

[5] S. Capone, M. Tufariello, L. Francioso, G. Montagna, F. Casino, A. Leoneand, P. Siciliano, Sensors and Actuators B: Chemical 179, 259-269 (2013)

[6] G. Botelho, I. Caldeira, A. Mendes-Faia, M. C. Clímaco, Flavour and Fragrance Journal 22, 414-420 (2007)
[7] L. Tat, P. Comuzzo, I. Stolfo, F. Battistutta, Food Chemistry 93, 361-369 (2005)

[8] B. Durteurtre, Champagne dalla tradizione ala scienza. Il método clássico passo a passo. Editora Eno-one, IT (2014)

[9] V. Ferreira, A base química do aroma do vinho: moléculas e sensações olfato-gustativas. Infowine - Revista Internet de Viticultura e Enologia 9 (2009)

[10] J. Torrens, M. Riu-Aumatell, S. Vichi, E. LópezTammames, S. Buxaderas, Journal of Agricultural and Food Chemistry58, 2455-2461 (2010)

[11] S. Pérez-Magariño, M. Ortega-Heras, M. BuenoHerrera, L. Martínez-Lapuente, Z. Guadalipe, B. Ayestarán, LWT - Food Science and Technology 61 , 47-55 (2015)

[12] S. Ganss, F. Kirsch, P. Winterhalter, U. Fischer, H.G. Schmarr, Journal of Agricultural and Food Chemistry 59, 2524-2533 (2011)

[13] H. Alexandre and M. Guilloux-Benatier, Australian Journal of Grape and Wine Research 12, 119-128 (2006)

[14] P. Comuzzo, L. Tat, A. Tonizzo, F. Battistutta, Food Chemistry 99, 217-230 (2006) 